\title{
Lessons learned from a student-driven initiative to design and implement an Organ and Tissue Donation course across Canadian medical schools
}

\author{
Alexandra Fletcher ${ }^{1} \cdot$ Bing Yu Chen ${ }^{2} \cdot$ David Benrimoh $^{3} \cdot$ Sam Shemie $^{4} \cdot$ Stuart Lubarsky $^{5}$ \\ Published online: 1 October 2018 \\ (c) The Author(s) 2018
}

\begin{abstract}
The competencies required of the well-trained physician are constantly evolving, and medical education must adapt accordingly. In response, a growing number of influential medical education licensing and accreditation bodies have proposed frameworks that outline society's expectations of physician competencies. In Canada, undergraduate and graduate curricula have undergone major changes to meet the specifications of the CanMEDS framework, and similar efforts are underway internationally. Nonetheless, ensuring the values enshrined within such frameworks become integral to a physician's identity remains challenging. We believe that student-led curricular initiatives represent a novel way of approaching this shifting medical education landscape.

In this article, we reflect on lessons we learned as medical students spearheading an initiative to change how organ and tissue donation is taught in Canadian medical schools. Citing relevant medical education literature where applicable, we include a detailed description of our approach as a roadmap for students contemplating their own curricular innovations. By outlining the factors influencing this project's implementation, as well as the benefits and limitations of student participation in curriculum reform, we offer educators a fresh perspective on optimizing the student role in this important process. Ultimately, the authors argue that not only can student participation render curricular content more accessible to learners, but that the responsibilities students take on in this role naturally lead to the development of CanMEDs-based competencies such as advocacy, scholarship, and inter-professionalism.
\end{abstract}

Keywords Undergraduate medical education - Peer-assisted learning - Course design - Competency development . Advocacy $\cdot$ Organ donation

The first two authors contributed equally to this work.

Editor's Note: Commentary by Zac Feilchenfeld. https://doi.org/10.1007/s40037-018-0453-6

Electronic supplementary material The online version of this article (https://doi.org/10.1007/s40037-018-0454-5) contains supplementary material, which is available to authorized users.

Alexandra Fletcher

alexandra.fletcher@mail.mcgill.ca

1 Faculty of Medicine, McGill University, Montreal, QC, Canada

2 Department of Neurology, McMaster University, Hamilton, ON, Canada

3 Department of Psychiatry, McGill University, Montreal, QC, Canada

4 Pediatric Intensive Care Unit, McGill University Health Center, Montreal, QC, Canada

5 Neurology Unit, Montreal General Hospital, Montreal, QC, Canada

\section{Introduction}

In recent years, medical schools are increasingly attempting to incorporate peer-assisted learning, an umbrella term for activities such as peer teaching, resource development, and curricular research $[1,2]$. There is sound evidence supporting the benefits of peer-assisted learning on communication skills development, peer teacher and learner satisfaction, and resource utilization [1]. However, much of the research focuses on near-peer teaching, and pays scant attention to the role of student involvement in course development and evaluation [2].

In this article, we provide a student perspective (BYC, $\mathrm{AF}$ ) on student-led curricular design by reflecting on our initiative to develop an Organ and Tissue Donation course for undergraduate medical education. We argue that with appropriate mentorship, not only can student participation make curricular content more learner-friendly, but the responsibilities students take on in this role naturally lead to 
Table 1 A summary of lessons learned

For medical students

- Choose a single, well-defined topic that you are motivated to commit to.

- Defining specific learning objectives, establishing a content blueprint, and developing appropriate teaching points requires a broad and preferably inter-disciplinary review process, as different stakeholders will have different and valuable perspectives. Seek advice from many sources, including both content-specific and medical education experts. This will be the beginning of your network.

- Ground your work in appropriate research. Conducting a literature review will help refine the project's aims and identify strategies to achieve them. Collecting baseline data will help define your educational focus and measure the impact of your work.

a. Not only will these results influence faculty decisions regarding the validity of your work, but they are also the basis for any publications.

- When collaborating with other students, as a general rule in project management, empowering those involved is more effective than directing orders.

- Ensuring the long-term sustainability of your work requires high-level policy change. This is facilitated if you are able to identify motivated peers that can take over when you have to move on. Additionally, being mentored by a large organization is often associated with increased resources and opportunities to scale-up.

- Endorsement adds important weight to the credibility of your work, so actively seek opportunities to showcase your work and receive funding support

For medical educators

- Consider how students' topics of interest might be aligned with curricular objectives.

- Encourage students to develop a scholarly, evidence-based approach to educational innovations.

- Emphasize that the development of educational interventions should be informed by evidence from the medical education literature inasmuch as healthcare interventions are guided by the medical literature.

- Provide literature on the curricular design process, survey development and needs assessments (Medical education-specific guides are readily available (e.g. AMEE))

- Explore with students the notion of 'validity' as an evidence-based 'argument' supporting or refuting the defensibility of an educational tool, program or intervention [13].

- Encourage students to devise strategies for ongoing course or program evaluation through the introduction of relevant frameworks, such as Kirkpatrick's [19].

- Guide students toward relevant medical education conferences and award opportunities

the development of competencies common to most physician-competency frameworks [3]. Please see Tab. 1 for a summary of our reflections. Using the language of CanMEDS, we focus on advocacy, scholarship and interpersonal skills [4].

\section{Approach}

\section{Initiating the project}

This project was conceived in 2014 during our mandate as our faculty's public health officers. We chose to focus on organ and tissue donation in undergraduate medical education, a relatively well-defined topic that we believed would stimulate the interest of our peers. Our starting point was to contact a local organization with extensive experience in donation advocacy. Ultimately, this meeting established an ongoing partnership and represented our first link to the organ and tissue donation community.

\section{Defining the educational needs of the medical student population}

As we wanted our recommendations for curricular change to be evidence-based, SDS, a clinician-researcher and donation advocate, helped guide our literature review of healthcare student and professional knowledge of organ and tissue donation. We then developed a needs assessment survey to measure medical student knowledge on this subject, including the ability to identify a potential donor, a competency integral to the Medical Council of Canada graduation objective 109-10: '[If] brain death has occurred, ensure that the appropriate donation protocol be activated.' [5]. Students could also write down topics they believed should be taught during undergraduate medical education. In addition, a modified version served as our program evaluation tool. It was circulated following our faculty's pilot lecture on organ and tissue donation, taught by SDS within the second year neurology block. Following the Kirkpatrick model of program evaluation, it included 'Reaction' and 'Learning' measures addressing the perceived importance of this subject in undergraduate medical education and change in knowledge scores, respectively [6].

Supervised by a member of McGill's Centre for Medical Education (SL), we then developed a survey for all Canadian medical faculties designed to dovetail the student and faculty perspectives on organ and tissue donation education.

\section{Producing materials for the course proposal}

Our literature review culminated in the development of a proposal for an Organ and Tissue Donation course containing a detailed list of learning objectives (see Appendix A of the online Electronic Supplementary Material). The results of our needs assessment refined the learning 
objectives pertaining to the donation procedure (e.g. donor identification and referral), bioethical considerations, and end-of-life communication. To ensure the proposal reflected the realities of donation, we consulted many stakeholders, including donation advocates, physicians and nurses.

The stakeholder consultation step helped validate our educational program [7]. First, by consulting widely and undertaking an iterative review process, the final product is a representative blueprint of what donation experts believe medical students should know-evidence of its face validity [8]. Second, and perhaps more importantly, the networking process itself built valuable grassroots support for our efforts, garnering evidence supporting its catalytic validity - 'the degree to which the process re-orients, focuses, and energizes participants [...] in order to better transform it.' [8].

\section{Course dissemination across Canadian medical schools}

To improve the visibility of our work, we sought official endorsement from our proposal's reviewers. We then drafted position papers outlining the need for mandatory education on organ and tissue donation, which were adopted by national medical student [9] and professional [10] organizations. This flurry of activity created what John Kotter describes as 'a sense of urgency' [11], facilitating our project's dissemination.

Local leadership was critical to dissemination across Canada because the process is highly faculty-dependent. Control was delegated to self-governing groups composed of students with whom we had collaborated to draft the position papers. Their early engagement in shaping the project's vision empowered them to approach their respective faculties about incorporating elements of our proposal $[8,11]$ - further evidence of the project's catalytic validity [8].

As the process was rather labour intensive, it could only succeed if students were empowered with a sense of ownership [11]. To build leadership, we teleconferenced regularly and provided research mentorship [11]. Overall, we found great inter-faculty variability regarding attitudes towards student-led initiatives (and sometimes organ and tissue donation), resulting in heterogeneous levels of progress. Currently, 11 out of 17 Canadian faculties have approved curricular changes. These figures suggest our approach has been quite successful (Kirkpatrick's 'Behaviour' level) [6]. Evaluating the long-term impact on donation rates ('Results', the highest level of the Kirkpatrick model) requires further investigation [6].

\section{Laying the groundwork for sustainability}

Individual faculty level The results of our student surveys allowed us to mount an evidence-based argument to our faculty's curriculum committee about the validity of our project's aims, ensuring that the lecture gained a permanent spot within the curriculum [7]. Moreover, since our survey indicated students felt unprepared to discuss organ and tissue donation, the committee further recommended it be included within a module on 'Delivering Bad News' in the fourth year.

Organizational level The adoption of the position papers we drafted on mandatory training in organ and tissue donation in undergraduate medical education by student organizations [9] taps into their institutional memory, mandating them to invest resources into continuing our work. On the faculty side, our survey of medical faculties, serving as both a needs assessment and a strategy development tool, helped us determine what would most help faculties improve the content of their curriculums. As a result, we are currently working on producing core competencies in organ and tissue donation for graduating medical students.

\section{Discussion}

As exemplified by CanMEDS [4], medical schools face the task of producing graduates who are not 'just' medical experts. In order to foster the type of professional identity that embodies these competencies within the 4 years typically allotted to undergraduate medical education, they must be appreciated as interconnected, rather than independent 'measurable tasks' [12]. Our experiences have led us to believe that active involvement in curricular design is a powerful way of integrating these competencies.

\section{Developing new competencies}

Advocacy There is widespread endorsement by physician organizations for integrating advocacy into competency frameworks [13, 14], and faculties have made efforts to adjust their curricula accordingly $[14,15]$. However, it would appear that this strategy needs fine-tuning-for instance, a survey of residents trained within a CanMEDS-defined curricula found the majority do not engage in advocacy [14, 16]. This has partially been attributed to how it is taught, often via didactic lectures on the social determinants of health while neglecting 'practical activism' skills (e.g. effective letter writing, negotiating with policymakers) [13, $15,17]$.

The increasing trend to include students in advocacy teaching may indicate the tides are turning $[1,15,18-21]$. 
There is much to be gained: students benefit from servicelearning experiences [17] which can be formalized as scholarly interactions by conducting interviews and focus groups [1]. For example, we heard eye-opening stories from donor families and recipients, and drew from these experiences by inviting them to address our class. In addition, we worked to produce 'practice-level' changes through the dissemination of training materials for medical students [14]. To ensure the longevity of these efforts, we engaged in 'community and systems-level activism' by liaising with larger organizations [14].

Scholarship Authentic research experience is considered beneficial because it provides an opportunity for students to gain an appreciation for the methodologies involved, to interpret medical literature, and to foster interest in an academic career [22, 23]. Despite this, a 2015 systematic review found that although the majority of students (72\%) are somewhat interested by research, among those who actually engaged, the majority did so to make their residency application more competitive [24].

In light of attitudes like these, many faculties already employ various strategies to encourage student involvement in scholarly pursuits [22-24], traditionally in fundamental or clinical research fields [23, 24]. Although we support these efforts, we believe that widening the opportunities offered has the potential to engage a greater diversity of students. Due to the dynamic and multi-faceted nature of the work, students involved in curricular design develop a broad research skillset $[2,12]$. In our case, beyond content knowledge, we learned about the medical education methodologies for our needs assessment, course development and evaluation process. We also became more proficient at research-related activities, such as preparing manuscripts and presenting our work.

What kept us motivated was this project's translational nature, which is common to advocacy-themed research [13]. As translational work requires effective stakeholder engagement, we were held accountable to a large group of people who had devoted time to helping us succeed. We also got to experience the satisfaction of witnessing our work being translated into action (first within our own milieu, then across Canada). Finally, our research experience was reinforced by an emotional dimension. We discovered that conflict can arise between research and advocacy because of their differing goals- to uncover 'truth' vs. to promote a cause for noble but potentially biased reasons. Although we admittedly found it challenging to temper our advocacy instinct, we ultimately embraced the responsibility of 'wearing two hats' once we understood the synergy between them. As neatly put by Egon Guba: 'Relevance without rigor is no better than rigor without relevance' [8].
Interpersonal skills Collaboration, professionalism and leadership: Leading such a large-scale project required interactions with our many collaborators to be managed diplomatically, as any breach in professionalism could undermine an important relationship. To do this effectively without alienating or overburdening anyone meant identifying the most appropriate communication language, medium and frequency for each collaborator depending on their role [11]. The interpersonal skills we have acquired are invaluable, as literature on the benefits of peer-assisted learning [2] and service-learning [17] have shown.

\section{Benefits and limitations of student-led curricular design}

In addition to the potential for competency development, student-led curricular design is an opportunity to improve the quality of curricular content and teaching methods, and may be interesting from a resource allocation perspective. However, important barriers must be contended with, notably lack of expertise and high rate of student turnover.

Impact on the curriculum The theoretical basis of peer-assisted learning is the 'cognitive congruence' model, which postulates that student-designed curricula tend to be more student-centred, as students can identify a different set of needs than faculty $[1,25]$. This is illustrated by the fact that in most student-led projects [1, 18-20], including our own, it was the students who perceived a gap in their curriculum. When developing course content, students usually lack content expertise and compensate by reaching out to stakeholders (face validity [8]), partially overcoming bias [7]. In our case, our significant stakeholder engagement efforts facilitated the project's dissemination across Canada. To our knowledge, no other student-led project has achieved such widespread adoption. With regard to feedback, as students tend to provide more honest appraisals of peer-developed resources, this may lead to more meaningful program evaluation practices [25].

Resource allocation Securing the resources necessary for student-led curricular reform, particularly the commitment of dedicated supervisors to provide longitudinal mentorship, may prove difficult $[1,2]$. At the same time, however, as long as there is such a mentor, peer-assisted learning projects have consistently shown that students are capable of producing quality material that is both well received by learners and cost-effective [1, 18-20].

Curricula may take years to elaborate and must be tended to longitudinally, so student turnover is another important consideration [19]. We partially overcame this through our sustainability efforts, but despite this, the project is complex to manage and relies on our specific relationships with 
various individuals. It remains a challenge finding students who are able to continue our work, although the content already in place is secure. Had this project been initiated by faculty, there would likely have been better continuity $[18,20,21]$.

\section{Conclusion}

We hope that our honest presentation of what we have learned, including our missteps, is useful to the reader. To the enthusiastic medical student, we advise you find a balance between dogged advocacy and rigorous science. To the medical educator, we hope this article encourages you to take on the demanding yet rewarding task of supervising well-intentioned students and moulding them into novice medical education innovators.

Conflict of interest A. Fletcher, B.Y. Chen, D. Benrimoh, S. Shemie and S. Lubarsky declare that they have no competing interests.

Open Access This article is distributed under the terms of the Creative Commons Attribution 4.0 International License (http:// creativecommons.org/licenses/by/4.0/), which permits unrestricted use, distribution, and reproduction in any medium, provided you give appropriate credit to the original author(s) and the source, provide a link to the Creative Commons license, and indicate if changes were made.

\section{References}

1. Furmedge DS, Iwata K, Gill D. Peer-assisted learning—beyond teaching: How can medical students contribute to the undergraduate curriculum? Med Teach. 2014;36:812-7.

2. Ross MT, Cameron HS. Peer assisted learning: a planning and implementation framework: AMEE guide no. 30. Med Teach. 2007;29:527-45.

3. Albanese MA, Mejicano G, Mullan P, et al. Defining characteristics of educational competencies. Med Educ. 2008;42:248-55.

4. Frank J, Snell L, Sherbino J. CanMEDS 2015 physician competency framework. Ottawa: Royal College of Physicians and Surgeons of Canada; 2015.

5. Medical Council of Canada. Objectives for the qualifying examination. Head trauma / brain death / transplant donations. 2017. apps.mcc.ca. Accessed 4 Nov 2017.

6. Praslova L. Adaptation of Kirkpatrick's four level model of training criteria to assessment of learning outcomes and program evaluation in higher education. Educ Assess Eval Account. 2010;22:215-215.

7. Moss PA, Girard BJ, Haniford LC. Validity in educational assessment. Rev Res Educ. 2006;30:109-62.

8. Lather P. Issues of validity in openly ideological research: between a rock and a soft place. Interchange. 1986;17:63-84.

9. Chen BY, Fletcher A, Damji AN, et al. Resolution 20: organ and tissue donation in Canadian undergraduate medical education. 2016 Canadian Federation of Medical Students Spring General Meeting; April 15-16; Montreal. 2015. Position paper.

10. Katchikian A. Delegate motion 5-1: mandatory training on organ donation for medical students and residents at all Canadian medical schools. 148th Annual Meeting of the Canadian Medical Association Meeting; 2015 Aug 24-26; Halifax. 2015.

11. Kotter JP. Leading change: why transformation efforts fail. Harv Bus Rev. 1995;73:259-67.

12. Jarvis-Selinger S, Pratt DD, Regehr G. Competency is not enough. Acad Med. 2012;87:1185-90.

13. Earnest MA, Wong SL, Federico SG. Perspective: physician advocacy: What is it and how do we do it? Acad Med. 2010;85:63-7.

14. Dobson S, Voyer S, Hubinette M, et al. From the clinic to the community. Acad Med. 2015;90:214-20.

15. Benrimoh D, Warsi N, Hodgson E, et al. An advocacy and leadership curriculum to train socially responsible medical learners. MedEdPublish. 2016; https://doi.org/10.15694/mep.2016.000062.

16. Stafford S, Sedlak T, Fok MC, et al. Evaluation of resident attitudes and self-reported competencies in health advocacy. BMC Med Educ. 2010;10:82.

17. Stewart T, Wubbena ZC. A systematic review of service-learning in medical education: 1998-2012. Teach Learn Med. 2015;27:115-22.

18. Chew D, Jaworsky D, Thorne J, et al. Development, implementation, and evaluation of a student-initiated undergraduate medical education elective in HIV care. Med Teach. 2012;34:398-403.

19. Leeper H, Chang E, Cotter G, et al. A student-designed and studentled sexual-history-taking module for second-year medical students. Teach Learn Med. 2007;19:293-301.

20. Leung LB, Simmons JE, Ho J, et al. A five-year evolution of a student-led elective on health disparities at the Alpert Medical School. R I Med J. 2016;99:43-7.

21. Merridew N, Wilkinson D. Expanded partnerships between medical faculty and medical students: developing a global health curriculum as an example of 'student-led learning' at the University of Queensland, Australia. Med Teach. 2010;32:919-25.

22. Zee M, de Boer M, Jaarsma ADC. Acquiring evidence-based medicine and research skills in the undergraduate medical curriculum: three different didactical formats compared. Perspect Med Educ. 2014;3:357-70.

23. Green EP, Borkan JM, Pross SH, et al. Encouraging scholarship: medical school programs to promote student inquiry beyond the traditional medical curriculum. Acad Med. 2010;85:409-18.

24. Amgad M, Man Kin Tsui M, Liptrott SJ, et al. Medical student research: an integrated mixed-methods systematic review and metaanalysis. PLoS ONE. 2015;10:e127470.

25. Lockspeiser TM, O'Sullivan P, Teherani A, et al. Understanding the experience of being taught by peers: the value of social and cognitive congruence. Adv Health Sci Educ Theory Pract. 2008;13:361-72.

Alexandra Fletcher medical student at the Faculty of Medicine, McGill University, Montreal, Quebec.

Bing Yu Chen is a resident in the Division of Neurology, Department of Medicine, McMaster University, Hamilton, Ontario

David Benrimoh is a resident with the Division of Psychiatry, Department of Medicine, McGill University, Montreal, Quebec.

Sam Shemie is a paediatric critical care physician in the Division of Critical Care Medicine, Montreal Children's Hospital, McGill University Health Centre \& Research Institute, professor of pediatrics, McGill University, Montreal, Quebec and medical advisor for Deceased Organ Donation, Canadian Blood Services.

Stuart Lubarsky is a neurologist in the Department of Neurology at the Montreal General Hospital, assistant professor of neurology at McGill University, and core member at the Centre for Medical Education, McGill University, Montreal, Quebec. 